\section{Annual Meeting Placement Service Available Online}

For the first time, the Annual Meeting Placement Service will be available on the web. Employers and job applicants are asked to submit their preregistration placement information via a web site specifically designed for the Placement Service at www.apsanet.org/placement/. Job applicants will also be provided with space to include an electronic copy of their resume. The target date for launch of this site is June 1, 1999.

The goal of this new service is to provide Placement Service participants with access to information before their travel to Atlanta. Applicants will be provided access to a searchable database of job openings upon completion of their preregistration. Employers who have registered online will be able to review candidates' applications and resumes before they travel to the Annual Meeting in Atlanta. It is expected that employers and candidates will be able to contact each other to arrange interviews prior to the meeting. This should eliminate the rush that usually occurs the first day of the meeting.

Preregistered employers will also be given the opportunity to reserve an interview table before the meeting. A limited number of computer terminals will be available for use in the Placement Service area, along with a full complement of binders containing paper copies of all applications and job listings.

Online preregistration for the Placement Service begins around June 1 and ends August 9. Employers who register at the meeting must bring their job information on an 3.5" IBM disk. Jobs registered at the meeting will be added to the database and copied into binders. Candidates who register at the meeting will only have paper copies of their application and resume available for review.

\section{Personnel Service Newsletter Submission Process Now Online}

Beginning in July 1999, a new format for submission of listings and a change in the submission deadline will take effect. Employers will be REQUIRED to submit jobs via the web (www.apsanet.org/PSN/). The deadline for submitting listings will be extended to the 10th of the month (e.g., July 10 for the August issue). Institutions without access to the web should use email or send a 3.5" IBM floppy disk to submit listings. Disks should be mailed to the attention of the PSN Editor at APSA. Additional information will be announced in upcoming issues of PSN and in the Chair's Newsletter. It is anticipated these changes vill eliminate transcription errors and ensure more efficient production.

\section{Subscription Price for PSN Greatly Reduced for Web Users}

Beginning in June, subscriptions to the Newsletter will be offered in two ways: $\$ 20.00$ for the web-only version, and $\$ 40$ for both the web and printed versions. Overseas combined web and printed subscriptions will be $\$ 65$.

Members opting for web-only access will enjoy a $43 \%$ decrease in the price of a subscription in comparison with the print newsletter. Because members who reside outside the U.S. must pay for air mail foreign delivery, their current rate is $\$ 60$. If these members choose the web option, their subscription fee will drop by two-thirds.

Instructions for accessing the web version will be printed in the Newsletter and available on the web. Access to the web version of PSN is limited to individual subscribers. Departments will continue to receive the printed version. directed to Sean Twombly at twombly@apsanet.org. The deadline for receipt of completed applications is July 2, 1999.

\section{Two-Participation Rule for Annual Meeting Modified}

The APSA Council, on the recommendation of the APSA Committee on the Annual Meeting, decided to relax the two-participation rule for program participants beginning with the 2000 Annual Meeting in an effort to ease the workloads of the 50 or so division chairs that put together the Annual Meeting program each year.

The two-participation rule, originally adopted by the Council in 1987 and modified in 1995, limited individuals to two appearances on the Annual Meeting program, and counted presenting a paper, serving as a discussant, and chairing a panel as an appearance. The limits were imposed to broaden participation in all divisions of the official program and related group panels. Since 1996, division chairs have argued that counting service as a panel chair unreasonably extends the time they must spend assembling division panels. After considering the issue for several years, the Annual Meeting Committee recommended to the Council that serving as a panel chair no longer be counted against the two-participation rule. The Council adopted the recommendation at its April 17 meeting.

\section{Submission Process}

The Council also supported the Committee recommendation that the dual submission rule permitting individuals to submit the same proposal to two different divisions for consideration should not be changed. It is often unclear which division is the most relevant substantive division to receive a particular panel or paper proposal. As a result, the Council decided against limiting submissions to a single division, though such a limitation would have substantially reduced the workload of division chairs.

The Council strongly endorsed the Committee's decision to move to- 
ward a web-based submission process. The redesigned web process will contain built-in monitoring and confirmation processes that will notify submitters that their proposals have been received successfully. The new procedures will also allow submitters to check a public web site to obtain information on proposal and panel acceptances. Details on the new submission process will be included in the 2000 Annual Meeting Call for Papers that will appear in the Annual Meeting Final Program and the September issue of $P S$.

\section{PROceedings}

The growth in the size of the on-line papers archive, PROceedings, raised questions regarding the continuation of the Panel Paper Room. Beginning with the 2000 Annual Meeting, all panelists will be required to submit electronic copies of their papers to PROceedings. Whether panelists will continue to supply papers to the Panel Paper Room and whether meeting participants wish to have both the Paper Room and PROceedings are questions the Council hopes to answer in another year. Until then, the Council decided to continue operating the Panel Paper Room.

\section{Exhibit Hall}

Though anxious to support the exhibitors who make the Annual Meeting's Book Exhibit the largest offering of political science books and related materials in the world, the APSA Council did not respond favorably to exhibitors' requests that the Exhibit Hall be closed on Sunday, the final day of the Annual Meeting. Closing the Exhibit Hall on Sunday, Council members argued, was inconsistent with the Council's policy that every day of the Annual Meeting is equally important and should be treated as such.

\section{Holden Submits New Appointments; Announces Sabbatical for Rudder}

APSA President Matthew Holden submitted to the Council his interim

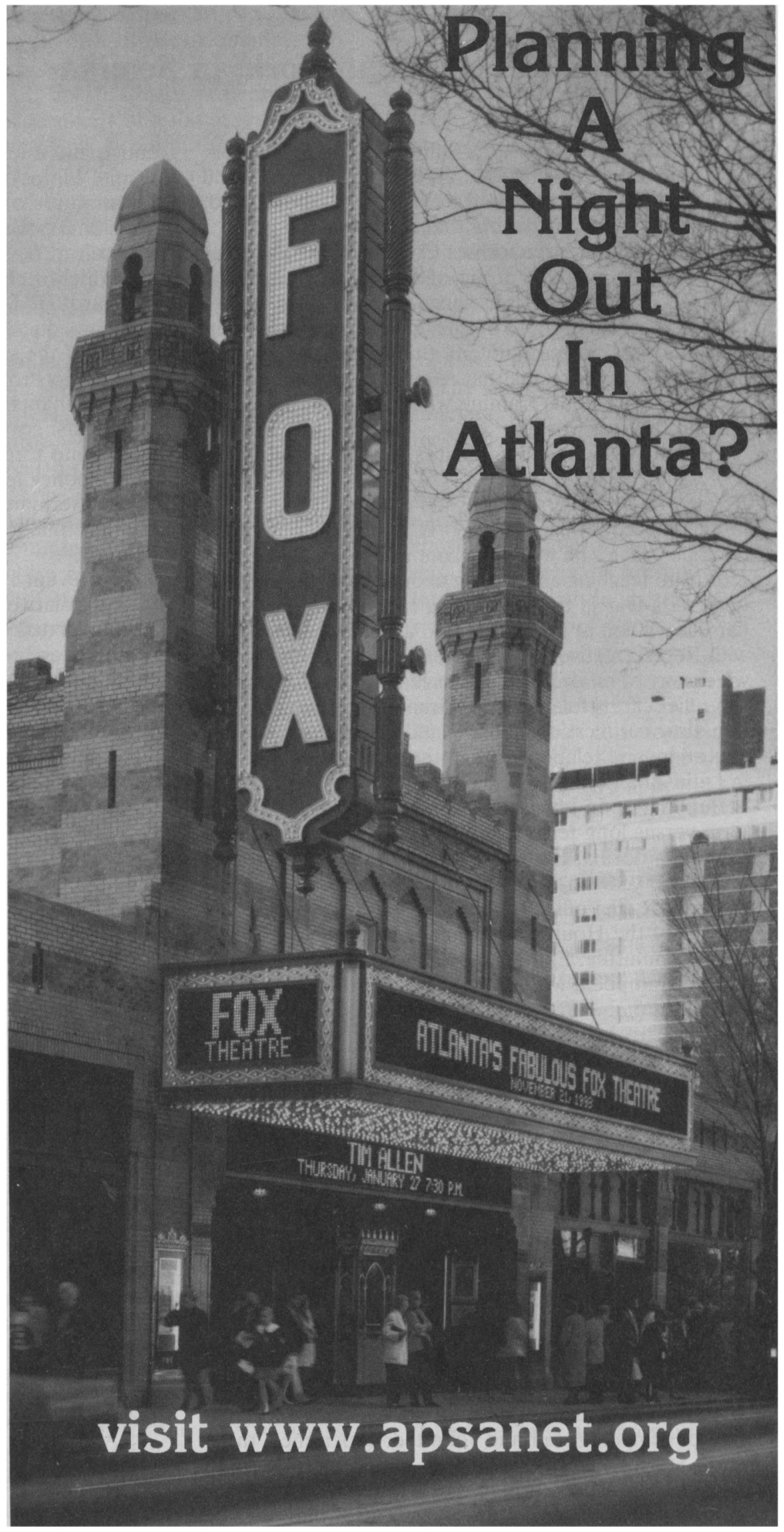

